Vol u m e $14 \quad \mathrm{Number} 1 \mathrm{P}$ a ges $35-45,2020$

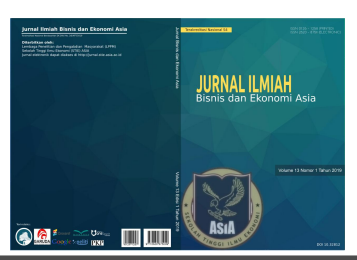

\title{
DETERMINASI KINERJA BANK UMUM KONVENSIONAL DI INDONESIA
}

\author{
Soeharjoto Soekapdjo*
}

Universitas Trisakti, Indonesia

\section{INFO ARTIKEL}

DOI:10.32812/jibeka.v14i1.148

ISSN-P: 0126-1258

ISSN-E: 2620-875X

Keywords: ROA, CAR, LDR, OER, NPL, TPF

\section{ABSTRACT}

Banking is a financial institution that makes a major contribution to economic development. Economic growth accelerated by good performance of the bank has an impact on improving public welfare. At this time, banks have complex problems, because they have a systematic risk impact and the development of digital technology, so need a good management, besides good performance demands to increase profits, also need prudential banking principles. Purpose of this research is to know about determination and another factor that have major contribution to prudential conventional commercial banking in Indonesia. Using monthly sequential time data, taken JK, BPS and BI from 2014-2018. Using regression methods, with ROA as dependent variable and CAR, LDR, OER, NPL, TPF as independent variable for the bank's internal factors, also macroeconomic factors using inflation, exchange rates, and GDP. Result shown that OER, inflation, the exchange rate has a negative influence with $R O A$, while $L D R$, TPF has a positive influence on ROA. CAR, NPL, exchange rate, and GDP variables do not affect $R O A$. The biggest contribution factor for performance of conventional bank is inflation, OER, LDR, TPF, and exchange rate. Banks improving performance, inseparable from external and internal factors, especially competition in the digital era, and need breakthrough in innovation by utilizing digital technology to increase efficiency and public trust.

\section{ABSTRAK}

Perbankan merupakan institusi keuangan yang memberikan kontribusi besar dalam pembangunan ekonomi. Kinerja bank yang baik akan mempercepat pertumbuhan ekonomi yang berdampak pada peningkatan kesejahteraan masyarakat. Pada saat ini, bank memiliki permasalahan yang semakin kompleks, karena memiliki dampak systematic risk dan semakin berkembangnya teknologi digital, sehingga dalam pengelolaannya disamping adanya tuntutan kinerja yang baik untuk dapat meningkatkan profit, juga perlu memperhatikan prinsip kehati-hatian. Dalam penelitian ini, mempunyai tujuan untuk mengetahui determinasi dan faktor yang memberikan kontribusi terbesar pada kinerja bank umum konvensional di Indonesia. Datanya menggunakan runtut waktu, dalam bentuk bulanan pada 2014-2018, yang bersumber dari OJK, BPS, dan BI. Metodenya menggunakan regresi, dengan variabel dependen ROA dan variabel independen untuk faktor internal bank menggunakan CAR, LDR, OER, NPL, DPK serta faktor ekonomi makro menggunakan inflasi, kurs, dan PDB. Adapun hasilnya adalah OER, inflasi, kurs mempunyai pengaruh negatif dengan ROA, sedangkan LDR, DPK mempunyai pengaruh positif dengan ROA. Untuk variabel CAR, NPL, kurs, dan PDB tidak berpengaruh terhadap ROA. Faktor yang merberikan kontribusi terbesar terhadap kinerja bank konvensional meliputi inflasi, OER, LDR, DPK, dan kurs. Bank dalam meningkatkan kinerjanya tidak terlepas dari faktor ekternal dan internal, apalagi di era digital persaingannya semakin ketat, sehingga diperlukan terobosan melalui inovasi dengan memanfaatkan teknologi digital guna meningkatkan efisiensi dan kepercayaan masyarakat. 


\section{Pendahuluan}

Perbankan sebagai lembaga intermediary mempunyai peran yang strategis dalam menunjang pembangunan nasional. Sistem keuangan yang semakin maju berdampak pada semakin kompleks permasalahan yang dihadapi bank, sehingga dibutuhkan kehati-hatian dalam melaksanakan perannya. Apalagi, dengan semakin berkembangnya teknologi digital, perbankan semakin dituntut untuk melakukan inovasi dalam melakukan pelayanan terhadap nasabah. Bagi perbankan yang dapat menguasai teknologi, peluang ini akan memberikan dampak positif, berupa efisiensi yang dapat menunjang peningkatan kinerja bank.

Globalisasi memberikan multiplier effect yang cepat terhadap perkembangan masyarakat, karena akan mengubah segala aspek kehidupan. Kesemunya tidak terlepas dari adanya borderless, yang menyebabkan hilangnya batasan yang mengatur perilaku masyarakat. Kondisi ini, juga terjadi dalam bidang keuangan, dengan adanya liberalisasi akan terbentuknya financial integration, yang merupakan dampak dari cross border banking (Lucky et. al., 2017).

Kondisi ekonomi makro yang tidak menguntungkan akan memberikan kotribusi yang besar terhadap krisis perbankan (Castro, 2013). Bank mengalami ini, karena adanya dampak dari perubahan kondisi ekonomi makro, yang bergerak dari kondisi stabil menjadi resesi, sehingga akan terjadi interaksi antara kondisi ekonomi, keuangan dan struktur lembaga yang semakin melemah (Llewellyn, 2002). Dengan demikian, perbankan akan kesulitan likuiditasnya yang akan berdampak pada kredit macet. Kesemuanya, terjadi karena tidak terlepas dari adanya dampak faktor eksternal dan internal yang ada pada sistem keuangan negara (Fischer, 1997). Macfarlane (1999), mengungkapkan bahwa penyebabnya adalah adanya keterkaitan resiko dari elemen yang ada di sistem keuangan, yakni lingkungan ekonomi makro, lembaga finansial, pasar keuangan, lembaga pengawas, dan sistem pembayarannya. Hal ini yang juga terjadi di Indonesia. Perbankannya sendiri memiliki peran sebagai financial intermediaries untuk membialayai external financing bagi perusahaaan (Bodie dan Marton, 2000). Demirguc-Kunt, dan Detragiache (1998) mengungkapkan bahwa keterpurukan perbankan yang dapat dikategorikan krisis apabila mengalami satu dari empat hal, yakni rasio aset bermasalah terhadap total aset melampaui sepuluh persen, biaya penyelamatan perbankan sampai dua persen dari PDB, permasalahan perbankan yang berdampak pada nasionalisasi bank, dan adanya rush.

Kepercayaan masyarakat merupakan modal utama perbankan dalam memenangkan persaingan pasar yang semakin ketat. Padahal, persingan yang terjadi, tidak hanya pada kepemilikan aset saja, namun sudah bergeser ke inovasi, pengetahuan, pengelolaan organisasi, serta research and development sumber daya manusianya. Hal ini, menunjukkan bahwa sudah terjadi pergeseran dari aset berwujud kepada intellectual capital. Maka dari itu, untuk memenangkan pasar diperlukan perbaikan dalam pengoperasian bank secara sehat dan efisien, melalui perbaikan manajerialnya.

Perbankan yang handal merupakan indikator stabilitas dan pertumbuhan ekonomi yang baik (Halling dan Hayden, 2006). Kinerja dan reputasi bank, dipengaruhi oleh resiko likuiditas (Jenkinson, 2008). Pada era ini, resiko likuiditas dijadikan perhatian yang serius bagi bank. Adanya kompetisi yang tinggi dalam menghimpun dana pihak ketiga, berdampak pada struktur manajemen yang kuat, yakni bank memiliki kualitas asset yang baik, pendapatan dan modal yang cukup, dengan memperhatikan likuiditasnya (Crowe, 2009). Namun, Peraturan Bank Indonesia No. 6/10/PDI/2004 dalam menerapkan Bank for International Sattlement, juga memberikan kebebasan bagi bank sentral dalam menerapkan penilaian perbankan. Bank Indonesia sendiri, menilai tingkat kesehatan bank melalui CAMELS.

Dalam industri perbankan banyak pihak yang terkait, sehingga akan terjadi conflict interest dalam pengambilan keputusannya. Pihak pemegang saham, memiliki kepentingan memperoleh keuntungan dengan cara mengambil resiko dengan mengorbankan pihak lain (deposan, LPS, dan pemegang saham minoritas) dan manajemen bisa mengorbankan kepentingan pemegang saham, debitur dan kepentingan bank. Padahal, dalam industri perbankan, pihak banker (agent) mempunyai sumber informasi yang lebih lengkap dan akurat daripada pendirinya (principal). Jadi, untuk meningkatkan profitabilitas, para 
pengelola bertugas mengoptimalkan pemanfaatan aset. Dengan artian, dapat memecahkan konflik antara liquidity versus profitability yang banyak mengandung resiko. Kemacetan dari pembayaran akan berdampak pada resiko likuiditas (Diamond dan Rajan, 2001). Resiko ini, bukan saja bersumber dari perbankan sendiri, tetapi dapat juga berasal dari sumber lain, yakni makronya (Soeharjoto et. al., 2018). Adanya krisis likuiditas yang parah, akan berakibat adanya kebangkrutan, yang akan berdampak pada krisis keuangan.

Perbankan akan mendapatkan kepercayaan masyarakat apabila memiliki kinerja yang baik. Hal ini, terjadi karena kinerja keuangan bank merupakan gambaran dari kondisi keuangan bank pada periode tertentu, yang meliputi aspek penghimpunan dana dan penyaluran dana, dengan menggunakan indikator kecukupan modal, likuiditas, dan profitabilitas bank (Jumingan, 2006). Dengan demikian, kinerja bank memiliki dua indikator dan dimensi pokok, yakni dengan menggunakan indikator kualitas dan kuantitas, serta dimensi profitabilitas dan risiko (Rose, 2000). Rasio keuangan dipergunakan perbankan karena dapat digunakan sebagai indikator alat analisis, di dalam laporan keuangannya (Anshori ,2009). Keadaan ini, didukung dengan peraturan bank Indonesia No. 9/1/PBI/2007, yakni untuk penilaian bank menggunakan CAMELS (Capital, Asset, Management, Earning, Liquidity, dan Sensitivity Market Risk).

Profitabilitas merupakan indikator yang digunakan dalam menilai keberhasilan kinerja perbankan. Return on Asset (ROA) digunakan untuk mengukur profitabilitasnya (Brigham dan Houston, 2010). Namun, yang juga perlu diingat adalah jangan sampai hanya mengejar profit tanpa memperhatikan likuiditasnya, karena akan berdampak pada kredit bermasalah. Adanya aturan dari bank sentral di Indonesia, yang merujuk pada kebijakan Basel III, tentu akan membuat kondisi perbankan menjadi lebih safty. Dengan demikian, perlu dilakukan penelitian determinasi kinerja bank umum konvensional di Indonesia. Adapun faktor yang mempengaruhinya dapat disebabkan faktor internal banknya yang berupa CAR, LDR, OER, NPL, DPK dan faktor ekonomi makro yang berupa inflasi, kurs, produk domestik bruto (PDB).

CAR menunjukkan dana sendiri yang digunakan dalam menutupi resiko yang ada, akibat penanaman aktiva yang memiliki resiko, guna membiayai aktivitas banknya. Apabila CAR-nya besar, bank akan memperoleh keuantungan yang besar pula. Dengan demikian, CAR berpengaruh positif dengan ROA. Kondisinya sama dengan hasil penelitian Dincer et. al,. (2011), Akhtar et. al,. (2011), Ponco (2008), Sukarno dan Syaichu (2006).

LDR merupakan kemampuan dari bank untuk menyediakan dana kepada debiturnya, baik dengan modal sendiri ataupun dari masyarakat. Jadi, LDR merupakan kemampuan bank untuk mengatur likuiditas apabila nasabah hendak menarik dananya, padahal dananya sedang dipinjamkan pada pihak lain. LDR yang tinggi, akan semakin rendahnya kemampuan likuiditasnya, sehingga kemungkinan bank akan menghadapi kredit macet. Namun, apabila perbankan telah mememuhi kriteria LDR yang telah ditetapkan bank sentral, yakni menurut ketentuan BI, LDR maksimum bernilai 110 persen, tetapi idealnya berkisar antara 75-80 persen, sehingga semakin kecil LDR berarti bank tersebut kurang menyalurkan kreditnya dan bila LDR di atas 110 persen akan berakibat menekan CAR. Dengan demikian, LDR berpengaruh positif dengan ROA. Keadaan ini sesuai dengan penelitian Trinugroho et. al. (2014), Uremadu (2012), Sukarno dan Syaichu (2006).

OER mencerminkan perbandingan antara biaya operasi dengan pendapatannya. Biaya operasi diukur guna mengetahui efisiensi bank, sehingga dapat menekan biaya, maka keuntungannya juga akan meningkat. OER yang kecil berarti banknya efisien. Dengan demikian, OER mempunyai pengaruh negatif dengan ROA. Hal ini, sama dengan hasil penelitian Chou dan Buchdadi (2016), Prasetyo (2015), Curak et. al. (2012), Arimi dan Mahfud (2012), Olson dan Zoubi (2011), Sukarno dan Syaichu (2006).

NPL merupakan kemampuan dari manajemen bank dalam mengelola kredit bermasalah. Dengan demikian, semakin tinggi NPL berarti akan semakin besarnya kemungkinan akan terjadi kredit macet, sehingga akan menurunkan profitabilitas banknya. Jadi, NPL mempunyai pengaruh yang negatif dan signifikan terhadap ROA. Keadaan ini sesuai dengan penelitian Chou dan Buchdadi (2016), Prasetyo (2015), Dietrich dan Wanzenried (2014), Edo dan Wiagustini (2014), Arafat et. al. (2013), Joseph et. al. (2012), Puspitasari (2009). 
DPK merupakan uang yang dapat dikumpulkan oleh bank dari masyarakat. DPK yang ada di bank, kemudian dipinjamkan kepada pihak yang membutuhkan, sehingga bank akan memperoleh keuntungan dari bunga yang dikenakan. Semakin banyaknya DPK akan meningkatkan keuntungan bank. Dengan demikian, DPK mempunyai pengaruh positif dengan ROA. Keadaan ini, sama dengan hasil penelitian Irianti (2011), Hasanudin dan Prihatiningsih (2010), Pratama (2010).

Inflasi merupakan kecenderungan meningkatnya harga-harga keseluruhan barang dan berkelanjutan. Adanya inflasi, akan berdampak pada kenaikan biaya produksi dan akan meningkatkan resiko perusahaan ditambah menurunnya daya beli masyarakat, sehingga adanya keinginan dari perusahaan untuk mengurangi investasi, sehingga akan menurunkan profitabilitas Bank. Dengan demikian, inflasi memiliki pengaruh negatif dengan ROA. Kondisi ini, sama dengan hasil penelitian Ali et. al. (2011), Afanasieff et. al. (2002).

Kurs merupakan nilai atas suatu mata uang terhadap mata uang lainnya. Apabila mata uang mengalami peningkatan nilai akan terjadi apresiasi, sedangkan yang terjadi sebaliknya akan terjadi depresiasi. Apabila mata uang mengalami depresiasi, perusahaan yang banyak menggunakan konten impor, akan memicu peningkatan biaya produksi, sehingga akan mengurangi penjualan, kemudian akan menurunkan keuntungan perusahaan, sehingga perusahaan akan berhati-hati dalam berinvestasi. Ahirnya, perusahaan akan mengurangi pinjaman, sehingga akan berakibat keuntungan bank akan berkurang. Dengan demikian, kurs berpengaruh negatif dengan ROA. Kondisi ini, sesuai hasil penelitian Utu (2018) dan Khrawish et. al. (2011).

PDB dapat mempengaruhi kepercayaan nasabah terhadap bank. Adanya peningkatan PDB, akan meningkatkan saving DPK di bank. Semakin banyaknya DPK dan iklim usaha yang kondusif yang ditunjang dengan peningkatan daya beli masyarakat, akan meningkatkan investasi perusahaan, yang akan meningkatkan pinjaman ke bank, kemudian berdampak pada peningkatan profitabilitas bank. Dengan demikian, PDB mempunyai pengaruh positif dengan ROA. Kondisi ini, sesuai hasil penelitian Sahara (2013), Jamal et. al. (2012), Dietrich dan Wanzenried (2011), Ali et. al. (2011).

Perbankan merupakan institusi yang dapat memberikan multiplier effect yang besar terhadap keberhasilan pembangunan suatau negara, namun bila dalam pengelolaannya mengalami kendala, bahkan justru menjadi sumber systematic risk, yang berdampak pada krisis ekonomi. Untuk itu, perlu diketahui determinasi dan faktor yang memberikan kontribusi terbesar terhadap kinerja bank umum konvensional di Indonesia, agar dapat menunjang keberhasilan dalam mengelola bank.

\section{Metode Penelitian}

Penelitian determinasi kinerja bank umum konvensioanl di Indonesia, memakai data runtut waktu, berupa bulanan, yang berasal dari Otoritas Jasa Keuangan (OJK), Badan Pusat statistik (BPS), dan Bank Indonesia (BI), pada periode 2014-2018. Variabel dependen menggunakan ROA dan variabel independennya adalah CAR, LDR, OER, NPL, DPK, Inflasi, kurs, $\mathrm{PDB}$. Metode yang digunakan adalah regresi. Adapun model yang digunakan:

$R O A=\beta_{0}+\beta_{1} C A R+\beta_{2} L D R+\beta_{3} \mathrm{OER}+\beta_{4} N P L+\beta_{5} \mathrm{DPK}+\beta_{6} I N F+\beta_{7} \mathrm{KURS}+\beta_{8} \mathrm{PDB}+\varepsilon_{\mathrm{t}}$

Keterangan:

$\begin{array}{ll}\text { ROA } & =\text { Return on Asset. } \\ \text { CAR } & =\text { Capital Adequacy Ratio. } \\ \text { LDR } & =\text { Loan to Deposit Ratio. } \\ \text { OER } & =\text { Operational Efficieny Ratio. } \\ \text { NPL } & =\text { Non Performing Loan. } \\ \text { DPK } & =\text { Dana Pihak Ketiga. } \\ \text { INF } & =\text { Inflasi. } \\ \text { KURS } & =\text { Rupiah terhadap USD. } \\ \text { PDB } & =\text { Produk Domestik Bruto. }\end{array}$

Hipotesa:

$\mathrm{H}_{1}$ : CAR berpengaruh positif signifikn dengan ROA. 
$\mathrm{H}_{2}$ : LDR berpengaruh positif signifikan dengan ROA.

$\mathrm{H}_{3}$ : OER berpengaruh negatif signifikan dengan ROA.

$\mathrm{H}_{4}$ : NPL berpengaruh negatif signifikan dengan ROA.

$\mathrm{H}_{5}$ : DPK berpengaruh positif signifikan dengan ROA.

$\mathrm{H}_{6}$ : INF berpengaruh negatif signifikan dengan ROA.

$\mathrm{H}_{6}$ : KURS berpengaruh negatif signifikan dengan ROA.

$\mathrm{H}_{7}$ : PDB berpengaruh positif signifikan dengan ROA.

Model regresi dapat digunakan setelah dilakukan uji asumsi klasik dan hipotesa. Asumsi klasik menguji normal, autokorelasi, multikolinearitas, dan heteroskedastisitas. Apabila asumsi sudah terpenuhi, baru dapat dilanjutkan dengan uji hipotesa, yang meliputi goodness of fit, global (uji F), dan individu (t).

\section{III.Hasil Penelitian dan Pembahasan}

Kondisi internal bank konvensional di Indonesia masih pada taraf baik, karena memiliki ROA, CAR, LDR, OER, NPL, dan DPK yang masih memenuhi kriteria yang ditetapkan Bank Indonesia. ROA memiliki rata-rata 2,534535 persen yang masuk dalam kategori sangat sehat, karena berada di atas 1,5 persen. CAR memiliki rata-rata 25,90146 persen yang berada pada kategori sangat sehat, karena nilainya di atas 12 persen. LDR sangat sehat karena nilai rata-ratanya di atas 75 persen, yakni sebesar 102,8665 persen. NPL masuk dalam kategori sehat, karana nilai rata-ratanya 2,5855 persen yang berada antara 2-5 persen. DPK memiliki trend yang meningkat.

Untuk ekonomi makronya di Indonesia cukup kondusif karena masih dalam tahap stabil. Keadaan tersebut, yang disebabkan dengan inflasi yang rendah dengan rata-rata 0,350833 persen, kursnya relatif stabil yang rata-ratanya Rp. 13267,48 per USD dengan deviasi Rp. 868,7126 per USD, dan PDB yang memiliki trend yang semakin meningkat.

Tabel 1. Deskripsi Variabel Penelitian

\begin{tabular}{|l|c|c|c|c|c|c|c|c|c|}
\hline Variabel & ROA & CAR & LDR & OER & NPL & DPK & INF & KURS & PDB \\
\hline Mean & 2.534535 & 25.90146 & 102.8665 & 81.04190 & 2.585500 & 7593.324 & 0.350833 & 13267.48 & 2365.187 \\
\hline Median & 2.435400 & 26.37495 & 102.2750 & 81.40220 & 2.525000 & 7572.192 & 0.250000 & 13337.50 & 2365.932 \\
\hline Maximum & 3.240100 & 29.14260 & 110.8300 & 84.40040 & 3.290000 & 8885.309 & 2.460000 & 15227.00 & 2683.210 \\
\hline Minimum & 2.129400 & 22.59780 & 98.72000 & 76.23040 & 1.910000 & 6356.794 & -0.450000 & 11404.00 & 2057.830 \\
\hline Std. Dev. & 0.283385 & 1.839651 & 2.631445 & 2.141264 & 0.334068 & 926.2632 & 0.456517 & 868.7126 & 176.9934 \\
\hline
\end{tabular}

Sumber: Data Hasil Olahan

Asumsi klasik perlu dipenuhi sebelum dilakukan uji hipotesa. Uji normalitas terpenuhi karena prob. dari Jarque Berra 0,421>0,05, yang berarti data berdistribusi normal. Uji autokorelasi terpenuhi dengan menggunakan LM test diperoleh prob. 0,073>0,05, sehingga model terbebas dari autokorelasi. Uji multikolinearitas terpenuhi dengan nilai $\mathrm{VIF}<10$, yang berarti tidak ada multikolinearitas. Uji heteroskedastisitas terpenuhi dengan prob. white test $0,283>0,05$, sehingga terbebas dari heteroskedastisitas.

Pengujian model fit ditunjukkan dengan nilai adjusted $R^{2}$ sebesar 0,845 , yang artinya bahwa variasi atau perilaku dari variabel independen yaitu CAR, LDR, OER, NPL, DPK, inflasi, kurs dan PDB mampu menjelaskan variasi dari perilaku variabel dependen yaitu ROA sebesar 84,5 persen, sedangkan sisanya yaitu 15,5 persen adalah variasi dari variabel independen lain. Hasil ini menunjukkan bahwa model ROA untuk bank konvensional memiliki goodness of fit yang baik. Hasil pengujian global (uji F), ditunjukkan dengan nilai probabilitas dari $\mathrm{F}$ sebeasr $0,000<0,05$, yang artinya paling sedikit terdapat 1 variabel independen yang berpengaruh signifikan terhadap ROA.

Tabel 2. Hasil Estimasi Model ROA BankKonvensional

\begin{tabular}{l|l|l|l} 
Variable & Coefficient & Std. Error & t-Statistic
\end{tabular}

Prob. 


\begin{tabular}{|c|c|c|c|c|}
\hline C & 8.750280 & 1.080571 & 8.097833 & 0.0000 \\
\hline CAR & 0.019288 & 0.023888 & 0.807444 & $0.4232^{*}$ \\
\hline LDR & 0.014542 & 0.008245 & 1.763798 & $0.0838^{* *}$ \\
\hline OER & -0.050079 & 0.014171 & -3.533901 & $0.0009^{*}$ \\
\hline NPL & -0.124444 & 0.084435 & -1.473848 & $0.1467^{*}$ \\
\hline DPK & 0.000241 & 6.97E-05 & 3.457306 & $0.0011^{*}$ \\
\hline INF & -0.074496 & 0.035740 & -2.084387 & $0.0422^{*}$ \\
\hline KURS & -0.000142 & 3.69E-05 & -3.858834 & $0.0003^{*}$ \\
\hline PDB & -0.001584 & 0.000334 & -4.743499 & $0.0000^{*}$ \\
\hline R-squared & 0.866345 & \multicolumn{2}{|c|}{ Mean dependent var } & 2.534535 \\
\hline Adjusted R-squared & 0.845379 & \multicolumn{2}{|c|}{ S.D. dependent var } & 0.283385 \\
\hline S.E. of regression & 0.111432 & \multicolumn{2}{|c|}{ Akaike info criterion } & -1.413316 \\
\hline Sum squared resid & 0.633276 & \multicolumn{2}{|c|}{ Schwarz criterion } & -1.099164 \\
\hline Log likelihood & 51.39947 & \multicolumn{2}{|c|}{ Hannan-Quinn criter. } & -1.290434 \\
\hline F-statistic & 41.32231 & \multirow{2}{*}{\multicolumn{2}{|c|}{ Durbin-Watson stat }} & 1.471716 \\
\hline Prob(F-statistic) & 0.000000 & & & \\
\hline
\end{tabular}

Dependent Variable: ROA

$*=$ alpha $5 \% \quad * *=$ alpha $10 \%$

Sumber: Data diolah, 2020

Pengaruh CAR terhadap ROA, dari hasil perhitungan diperoleh nilai koefisien estimasi sebesar 0,0192, yang artinya CAR mempunyai pengaruh positif dengan ROA, dimana meningkatnya CAR berdampak pada peningkatan ROA dan sebaliknya, dengan menurunnya CAR akan menurunkan ROA. Dengan nilai t statistik sebesar 0,8074, diperoleh nilai probabilitas sebesar $0,4232>0,05$, yang artinya bahwa pengaruh dari CAR terhadap ROA tidak terbukti. Pengaruh LDR terhadap ROA, dari hasil perhitungan memiliki nilai koefisien sebesar 0,0145 , yang artinya meningkatnya LDR juga akan menaikkan ROA dan sebaiknya, menurunnya LDR akan menurunkan ROA. Dengan nilai t statistik sebesar 1,1763 , diperoleh nilai probabilitas sebesar $0,0838<0,1$, yang artinya bahwa LDR mempunyai pengaruh positif dengan ROA. Pengaruh OER terhadap ROA, dari hasil perhitungan diperoleh nilai koefisien estimasi sebesar minus 0,050, yang artinya meningkatnya BOPO akan menurunkan ROA dan sebaliknya, menurunnya OER akan meningkatkan ROA. Dengan nilai $t$ statistik minus 3,5339, diperoleh nilai probabilitas sebesar $0,0009<0,05$, yang bermakna ada pengaruh negatif antara OER dengan ROA. NPL dengan ROA, diperoleh koefisien estiimasi sebesar minus 0,1244, yang artinya meningkatkanya NPL akan menurunkan ROA dan sebaliknya, menurunnya NPL akan meningkatkan ROA. Dengan nilai $t$ statistik sebesar minus 1,4738, diperoleh nilai probabilitas sebesar $0,1467>0,05$, yang artinya bahwa NPL tidak terbukti berpengaruh dengan ROA. Pengaruh DPK terhadap ROA, dari hasil perhitungan diperoleh koefisien estimasi sebesar 0,0002 , yang artinya meningkatnya DPK menyebabkan naiknya ROA, dan sebaliknya, menurunnya DPK akan menurunkan ROA. Dengan nilai $t$ statistik sebesar 3,4573 diperolah probabilitas sebesar $0,0011<0,05$, yang bermakna ada pengaruh positif antara DPK dengan ROA. Pengaruh inflasi terhadap ROA, dari hasil perhitungan diperoleh nilai koefisien estimasi sebesar minus 0,0744 , yang artinya meningkatknya inflasi akan menurunkan ROA dan sebaliknya, menurunnya inflasi akan meningkatkan ROA. Dengan nilai $t$ statistik sebesar minus 2,0843, diperoleh nilai probabilitas sesbesasr $0,0422<0,05$, yang bermakna ada pengaruh negatif inflasi dengan ROA. Pengaruh kurs terhadap ROA, dari hasil perhitungan diperoleh koefisien estimasi sebesar minus 0,0001, yang artinya depreasi rupiah akan menurunkan dan sebaliknya, apresiasi rupiah akan menaikkan ROA. Dengan nilai t statistik sebesar minus 3,8588, diperoleh probabilitas sebesar $0,0003<0,05$, yang artinya bahwa bahwa kurs mempunyai pengaruh negatif dengan ROA.

PDB dengan ROA, diperoleh hasil perhitungan diperoleh nilai koefisien estimasi sebesar minus 0,0015 , yang artinya meningkatnya PDB akan menurunkan ROA dan sebaliknya, menurunnya PDB akan meningkatkan ROA. Keadaan ini, bermakna tidak 
terbukti PDB berpengaruh positif terhadap ROA. Dari beberapa faktor yang ada, terdapat lima faktor yang dapat memberikan kontribusi besar terhadap kinerja pada bank konvensional di Indonesia. Adapun faktor tersebut secara berurutan meliputi inflasi, DER, LDR, DPK, dan kurs. Hasil dari analisis perhitungan tersebut, terlihat bahwa kondisi eksternal dan internal ada yang memiliki pengaruh dan tidak terhadap ROA. Pihak bank perlu meningkatkan kinerja internalnya dan juga mengantisipasi dampak dari kondisi eksternalnya, sehingga bank dapat menjaga dan bahkan meningkatkan kinerjanya. Apalagi dengan semakin berkembanya era digital teknologi, semakin mempercepat laju perkembangan perbankan. Untuk itu, bank perlu melakukan inovasi dalam pemanfaatan teknologi digital agar dapat meningkatkan kinerja, guna memenangkan persaingan pasar yang semakin ketat. Dalam meningkatkan kinerja bank, perlu juga berhati-hati. Bank tetap perlu menjaga CAR sesuai dengan kesepakatan Basel III, agar terhindar dari krisis keuangan. LDR tetap perlu dijaga agar likuiditas bank tidak terganggu. OER perlu ditingkatkan dengan cara meningkatkan efisiensi dalam penggunaan SDM, SDA dan teknologi, melalui kerjasama dengan pihak yang terkait. NPL perlu diwaspadai agar jangan sampai terjadi kredit macet. DPK perlu ditingkatkan dengan memberikan pelayanan dan produk yang menarik. Bank dapat memprediksi dan bekerjasama dengan pemerintah dan masyarakat, guna menjaga kurs dan inflasi, disamping itu juga memberikan pinjaman terutama untuk pihak yang produktif dan terutama bergerak pada usaha kecil dan menengah, karena pihak ini justru telah memberikan kontribusi besar terhadap PDB, namun sudah terbukti tahan terhadap krisis global.

\section{Kesimpulan}

Perbankan merupakan institusi keuangan yang sensitif karena dengan adanya gejolak ekonomi makro, akan mempengaruhi kinerja internalnya, bahkan sampai dapat menyebabkan terjadinya systematic risk, yang berdampak pada krisis ekonomi di suatu negara. Untuk itu, perbankan perlu taat pada ketetapan bank sentral dan mengikuti perkembangan perbankan di dunia, yakni ketetapan Basel III. Kondisi perbankan konvensional di Indonesia cukup baik karena di dukung dengan ekonomi makro yang stabil dan internal banknya masih dalam taraf yang wajar, karena masih sesuai dengan ketetapan Bank Indonesia. Namun demikian, perlu adanya perhatian khusus terhadap faktor yang dapat mempengaruhi ROA, agar kondisinya dibuat semakin kondusif. Faktor yang dapat mempengaruhi ROA secara positif dan signifikan adalah LDR dan DPK, sedangkan OER, inflasi, dan kurs mempunyai pengaruh yang negatif dan signifikan. CAR, NPL, kurs, dan PDB tidak mempengaruhi ROA. Faktor yang merberikan kontribusi terbesar terhadap kinerja bank konvensional meliputi inflasi, DER, LDR, DPK, dan kurs. Dengan demikian, pada era digital teknologi saat ini, pihak bank perlu melakukan inovasi guna meningkatkan kinerjanya.

\section{Daftar Pustaka}

Arafat, M. Y., Warokka, A., Buchdadi, A. D., \& Suherman. (2013). Banking efficiency and performance: A test of banking characteristics in an emerging market. Journal for Global Business Advancement, Vol. 6(1). Retrieved from https://www.researchgate.net/publication/275590521_Banking_efficiency_and_perfor mance_A_test_of_banking_characteristics_in_an_emerging_market/download

Arimi, Millatina dan Mohammad Kholiq Mahfud. (2012). Analisis Faktor-Faktor yang Mempengaruhi Profitabilitas Perbankan (Studi Pada Bank Umum Yang Listed di Bursa Efek Indonesia Tahun 2007-2010). Diponegoro Journal of Management. Vol 1(2). Retrieved from https://ejournal3.undip.ac.id/index.php/djom/article/view/773/748

Ali, Khizer, Muhammad Farhan Akhtar dan Hafiz Zafar Ahmed. (2011). Bank Specific and Macroeconomic Indicators of Profitability-Empirical Evidence from the Commercial 
Banks of Pakistan. International Journal of Business and Social Science. Vol. 2(1). Retrieved from http://joc.hcc.edu.pk/faculty_publications/24.pdf

Akhtar, Muhammad Farhan, Khizer Ali, dan Shama Sadaqat. (2011). Factor Influencing the Probability of Conventional Banks of Pakistan. International Reseach Journal of Finance and Economic. Issue 66.

Afanasieff, T., Lhacer, P., Nakane, M. (2002). The determinants of bank interest spreads in Brazil. Working Paper. Banco Central di Brazil. Retrieved from https://core.ac.uk/download/pdf/6535936.pdf

Anshori, Abdul Ghofur. (2009). Perbankan Syariah Di Indonesia. Gadjah Mada University Press.

Bahtiar Usman, Syofriza Syofyan, Lucky Nugroho, dan Soeharjoto. (2018) Foreign Bank Penetration And Its Impact On Banking Industries. Eurasian Journal of Economics and Finance, Vol. 6(1). Retrieved from https://eurasianpublications.com/EurasianJournal-of-Economics-and-Finance/Vol.-6-No.1-2018/EJEF-7.pdf

Bodie, Zvi dan Robert C. Marton. (2000). Finance. International Edition. Prnetice Hall International, Inc. USA.

Berger, A. N., W. C. Hunter dan S. G. Time. (1993). The Efficiency of Financial Institution, A Riview and Preview of Reseach Past, Present and Furure. Journal of Banking and Finance. No. 17(2-3). Netrieved from https://www.sciencedirect.com/science/article/pii/037842669390030H

Chou, Te-Kuang dan Agung Dharmawan Buchdadi. (2016). Bank Performance and Its Underlying Factors: A Study of Rural Banks in Indonesia. Accounting and Finance Research. Vol. 5, No. 3.

Castro, Vitor. (2013). Macroeconomic Determinants of the Credit Risk in the Banking System: The Case of the GIPSI. GEMF Working Papers. Retrieved from http://gemf.fe.uc.pt/workingpapers/pdf/2013/gemf_2013-12.pdf

Curak, M., Poposki, K., \& Pepur, S. (2012). Profitability Determinants of the Macedonian Banking Sector in Changing Environment, Procedia - Social and Behavioral Sciences. 44. https://www.researchgate.net/publication/257716171_Profitability_Determinants_of_t he_Macedonian_Banking_Sector_in_Changing_Environment/download

Crowe, K. (2009). Liquidity Risk Management- More Importance Than Ever. Harland Financial Solution. 3. Retrieved from https://customercenter. harlandfinancialsolutions.com/Auth/Signin?ReturnUrl=\%2fKnowlegePortal\%2fSignin \%3freturnUrl\%3dpage\%253D

Dietrich, A., \& Wanzenried, G. (2014). The determinants of commercial banking profitability in low-, middle-, and high-income countries. Quarterly Review of Economics and $\begin{array}{llll}\text { Finance. } & \text { Vol. 54(3). } & \text { Retrieved }\end{array}$ https://www.sciencedirect.com/science/article/abs/pii/S1062976914000179

Dietrich, A., \& Wanzenried, G. (2011). Determinants of bank profitability before and during the crisis: Evidence from Switzerland. Journal of International Financial Markets, Institutions and Money. Vol. 21(3). 
Dincer, H., G. Gencer, N. Orhan dan K. Sahinbas. (2011). Performance Evaluation of The Turkish Banking Sector After The Global Crisis Via CAMELS Ratios. Procedia Social and Behavioral Sciences. $24 . \quad$ Retrieved from https://pdf.sciencedirectassets.com/277811/1-s2.0-S1877042811X00174/1-s2.0S1877042811015795/main.pdf

Diamond, D. dan R. Rajan. (2001) Liquidity Risk, Liquidity creation, and Financial Fragility: A Theory of Banking. The Journal of political Economy. Vol 109(2). Retrieved from https://faculty.chicagobooth.edu/raghuram.rajan/research/papers/doug1.pdf

Demirguc-Kunt, Asli dan Enrica Detragiache (1998). The Determinants of Banking Crises in Developing and Developed Countries. IMF Staff Papers. Quarterly journal of the IMF. Vol. 45(1). Retrieved from https://www.imf.org/external/Pubs/FT/staffp/1998/0398/pdf/demirguc.pdf

Edo, Deisy Setiawati Ratu dan Ni Luh Putu Wiagustini. (2014). E-Jurnal Ekonomi dan Bisnis Universitas Udayana. Vol. 3(11).

Fischer, Stanley. (1997). Central Banking: The Challenges Ahead Financial System Soundness. Financial and Development Journal. January.

Hasanudin, Muhamad dan Prihatiningsih. (2010). Analisis Pengaruh Dana Pihak Ketiga, Tingkat Suku Bunga Kredit, Non Performance Loan (NPL) dan Tingkat Inflasi Terhadap Penyaluran Kredit Bank Perkreditan Rakyat (BPR) di Jawa Tengah. Jurnal Teknis. Vol. 5(1). Retrieved from https://scholar.google.com/scholar?cluster=4544178271519153961\&hl=en\&oi=schol arr

Halling, M. dan Hayden, E. (2006) Bank Failure Prediction: A Two Step Survival Time Approach. Credit Conference. Austrian National Bank. Vienna. 31.

Irianti, Tjiptowati Endang. (2011) Pengaruh Rasio Kecukupan Modal, Likuiditas, dan Total Dana Pihak Ketiga Terhadap Tingkat Profitabilitas Perusahaan Perbankan. Jurnal Ilmiah Inkoma. Vol. 24(1). Retrieved from http://jurnal.undaris.ac.id/index.php/jurnal/article/view/16/14

Joseph, Mabvure Tendai, Gwangwava Edson, Faitira Manuere, Matibvu Clifford dan Komoyo Michael. (2012). Non Performance Loans in Commercial Banks: A Case of CBZ Bank Limited in Zimbabwe. Interdiciplinary Journal of Contemporary Reseach in Business. Vol. 24(1).

Jamal, Amer Azian Abdul, Mohd Rahimie Abdul Karim, Masyhuri Hamidi. (2012). Determinants of commercial Banks' Return on Asset: Panel Evidence from Malaysia. International Journal of Commerce, Business and Management. Vol. 1(3). Retrieved from https://www.researchgate.net/profile/Amer_Azlan_Abdul_Jamal/publication/2359622 56_Determinants_of_Commercial_Banks'_Return_on_Asset_Panel_Evidence_from_

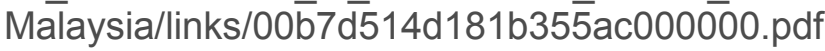

Jenkinson, N. (2008). Strengthening Regimes for Controlling Liquidity risk. Euro Money Conference on Liquidity and Funding Risk Management. London: Bank of England.

Jumingan. (2006). Analisis Laporan Keuangan. Bumi Aksara. 
Khrawish, Husni Ali, W. Z. Siam and Khrawish A. H. (2011). Determinants of Islamic Banks Profitability: Evidence from Jordan. Middle Eastern Finance and Economics Journal. (13). Retrieved https://scholar.google.co.id/scholar?cluster=5859517051379910063 from

Lucky Nugroho, Wiwik Utami, Caturida Meiwanto Doktorlina, Soeharjoto, dan engku Chandra Husnadi (2017). Islamic Banking Capital, Challenge to Increase Business Expansion (Indonesia Case). International Journal of Commerce and Finance. Vol. 3(2). Retrieved from http://ijcf.ticaret.edu.tr/index.php/ijcf/article/view/53/pdf_37

Llewellyn, D. (2002). An Analysis of the Causes of Racent Banking Crises. European Journal of Finance. 36.

Macfarlane, Ian J. (1999). Statement to Parliamentary Committee. Reserve Bank of Australia Bulletin. January.

Olson, Dennis and Taisier A. Zoubi. (2011). Efficiency and bank profitability in MENA countries. Emerging Markets Review._Vol. 12(2).

Prasetyo, Wawan. (2015). Analisis Faktor-Faktor Yang Mempengaruhi Profitabilitas Perbankan. Jurnal Ekonomi dan Studi Pembangunan. Vol. 7(1). Retrieved from http://journal.um.ac.id/index.php/jesp/article/view/5315/1970

Pratama, Billy Arma. (2010). Analisis Faktor-Faktor Yang Mempengaruhi Kebijakan Penyaluran Kredit Perbankan (Studi Pada Bank Umum di Indonesia, Periode 20052009). Tesis Universitas Diponegoro, Semarang. Retrieved from http://eprints.undip.ac.id/24059/1/Billy_Arma_Pratama.pdf

Puspitasari, Diana. (2009). Analisis Pengaruh CAR, NPL, PDN, NIM, BOPO, LDR, dan suku bunga SBI Terhadap ROA. Tesis. Universitas Diponegoro. Semarang. Retrieved from http://eprints.undip.ac.id/17071/1/DIANA_PUSPITASARI.pdf

Ponco, Budi, 2008, Analisis Pengaruh CAR, NPL, BOPO, NIM dan LDR Terhadap Roa. Tesis Universitas Diponegoro. Semarang. Retrieved from http://eprints.undip.ac.id/16854/1/BUDI_PONCO.pdf

Peraturan BI No. 9/1/PBI/2007 Sistem Penilaian Tingkat Kesehatan Bank Umum Berdasarkan Prinsip Syariah.

Peraturan Bank Indonesia No. 6/10/PDI/2004 tentang Sistem Penilaian Tingkat Kesehatan Bank Umum.

Rose, Peter S. 2000. Money and capital markets: Financial Institutions Instruments in the Global Marketpalace. Texas A\&M University.

Soeharjoto Soekapdjo, Lucky Nugroho, Ahmad Badawi, dan Wiwik Utami. (2018) Bad Debt Issues in Islamic Bank: Macro and Micro Influencing (Indonesia Cases). International Journal of Commerce and Finance. Vol. 4(1). Retrieved from http://ijcf.ticaret.edu.tr/index.php/ijcf/article/view/62/pdf_45

Sutrisno. (2016). Risiko, Efisiensi dan Kinerja Pada Bank Konvensional di Indonesia. Jurnal IImiah Akuntansi dan Bisnis. Vol. 11(2). Retrieved from https://ojs.unud.ac.id/index.php/jiab/article/view/24940/18090 
Sahara, Ayu Yunita. (2013). Analisis Pengaruh Inflasi, Suku Bunga BI, dan Produk Domestik Bruto Terhadap Return On Asset (ROA) Bank Syariah di Indonesia. Jurnal IImu Manajemen. Vol. 1(1). Retrieved from https://jurnalmahasiswa.unesa.ac.id/index.php/jim/article/view/1502/1133

Sukarno, Kartika Wahyu dan Muhamad Syaichu. (2006) Analisis Faktor-Faktor Yang Mempengaruhi Kinerja Bank Umum di Indonesia. Jurnal Studi Manajemen dan $\begin{array}{llll}\text { Organisasi. } & \text { 3ol. } & \text { Retrieved } & \end{array}$ https://ejournal.undip.ac.id/index.php/smo/article/view/4193

Trinugroho, I., Agusman, A., \& Tarazi, A. (2014). Why have bank interest margins been so high in Indonesia since 1997/1998 financial crisis. Research in International Business and Finance, 32.

Utu, La. (2018). Effect of Extern Factors on Return on Asset (ROA) in Banking Industry in Indonesia Stock Exchange. International Journal of Scientific and Engineering Research. Vol 9(12). Retrieved from https://www.ijser.org/researchpaper/EFFECTSOF-EXTERN-FACTORS-ON-RETURN-ON-ASSET-ROA-IN-BANKING-INDUSTRYIN-INDONESIA-STOCK-EXCANGE.pdf

Uremadu, Sebastian Ofumbia. (2012). Bank Capital Structure, Liquidity and Profitability Evidence from the Nigerian Banking System. International Journal of Academic Research in Accounting, Finance and Management Science. Vol. 2(1). Retrieved from https://pdfs.semanticscholar.org/2ea4/821dd35a84b160c72325eed44b0e124744c4.p df?_ga=2.170971680.1079358697.1562575843-1520202672.1562326459

Zeithaml, A., V. Parasuraman, A. and L. Berry L. (1985). Problems and Strategies in Services Marketing. Jurnal of Marketing. Vol. 49. (Spring).

www.bi.go.id

www.bps.go.id

www.ojk.go.id 